\title{
LA POLÍTICA CONSULAR EN ESTADOS UNIDOS: PROTECCIÓN, DOCUMENTACIÓN Y VINCULACIÓN CON LAS COMUNIDADES MEXICANAS EN EL EXTERIOR
}

\author{
CONSULAR POLICY IN THE UNITED STATES: \\ PROTECTION, DOCUMENTATION AND CONNECTION \\ WITH MEXICAN COMMUNITIES ABROAD
}

\begin{abstract}
LA POLITIQUE CONSULAIRE DU MEXIQUE AUX ÉTATS-UNIS POUR PROTÉGER LES COMMUNAUTÉS MEXICAINES À L'ÉTRANGER, LEUR PROCURER DES PAPIERS ET ÉTABLIR DES LIENS AVEC ELLES
\end{abstract}

\author{
Héctor Cárdenas Suárez \\ Goldman School of Public Policy, \\ University of California Berkeley \\ Heccard@berkeley.edu
}

Resumen: La política consular de México es una política pública de Estado que responde a problemas y oportunidades estructurales de la relación entre México y Estados Unidos, y que demuestra una fuerte continuidad a lo largo de los últimos gobiernos. Durante el sexenio del presidente Enrique Peña Nieto, la política consular respondió a problemas estructurales y sui generis relativos a la fuerte integración social y económica entre los dos países, a la presencia y desafíos específicos de la diáspora mexicana y a las cambiantes condiciones políticas en Eeuu. Su línea directriz ha sido la paulatina modernización de programas y servicios y la inversión en la expansión de la red consular. Viendo hacia el futuro, la política consular debe continuar su modernización y resolver el desafío de los recursos limitados.

Palabras clave: consular; política pública; política exterior; Estados Unidos; México; Secretaría de Relaciones Exteriores.

Aвstract: The consular policy of Mexico is a public policy of the State that responds to structural problems and opportunities in the relationship between Mexico and the United States, and which shows a strong continuity 
throughout recent governments. During the presidency of Peña Nieto, the consular policy responded to structural and sui generis problems related to the strong social and economic integration between the two countries, to the presence and specific challenges of the Mexican diaspora, and to the changing political conditions in the USA. Its general trend has been the gradual modernization of programs and services, and investment in the expansion of the consular network. Looking to the future, consular policy must continue to modernize and solve the challenge of limited resources.

Keywords: consular; public policy; foreign policy; United States; Mexico; Foreign Minister.

\section{Traducción de Gonzalo Celorio Morayta}

RÉsumé: La politique consulaire du Mexique est une politique publique qui réagit aux difficultés et aux opportunités ressortant des rapports MexiqueÉtats-Unis, et sa continuité a été remarquable le long des derniers gouvernements. Sous la présidence de Peña Nieto, cette politique s'est adressée aux problèmes structurels et singuliers qui relèvent d'une forte intégration sociale et économique des deux pays. Elle a répondu, en particulier, aux besoins de la diaspora mexicaine aux États-Unis, dans des conditions politiques toujours changeantes. L'un de ses fils conducteurs a été la modernisation graduelle des programmes et des services, liée aux investissements pour assurer la croissance du réseau consulaire. Dans l'avenir, cette politique devra poursuivre sa modernisation et surmonter les contraintes de ressources.

Mots clefs: consulaire; politique publique; politique étrangère; États-Unis; Mexique; Ministère des Relations extérieures.

Traducción de Bernardo Mabire

Fecha de recepción: diciembre de 2018

Fecha de aceptación: febrero de 2019 


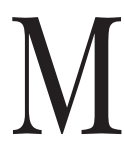

ÉXICO se distingue de otros países por la particular relevancia de su política consular -definida como la defensa de sus nacionales y de sus intereses en el exterior- con respecto al resto de su política exterior. Esto se debe a tres factores esenciales. Primero, que México cuenta con una de las diásporas más grandes del mundo, con más de 35 millones de personas mexicanas o de origen mexicano fuera de sus fronteras. Segundo, que gran parte de esa población vive en condiciones de vulnerabilidad, ya sea por su nivel socioeconómico o por su estatus migratorio irregular. Tercero, porque una mayoría abrumadora de esta población (más de 98.5\%), se encuentra en el territorio de un solo país, que es a la vez el principal socio y aliado de México y su principal foco estratégico. El efecto principal de estas tres circunstancias es que la política consular no pueda considerarse simplemente como un apéndice administrativo: su impacto es político y estratégico.

La política exterior de un país puede estudiarse desde distintos enfoques teóricos ${ }^{1}$ típicos de las relaciones internacionales, pero en el presente trabajo consideramos la política consular como una política pública y, por lo tanto, el enfoque está en la forma en que se define el problema que se propone resolver y en las herramientas técnicas, administrativas y financieras que se despliegan para su resolución. El análisis de políticas públicas, ${ }^{2}$ que también ha sido retomado en parte por la subdisciplina de análisis de política exterior, ${ }^{3}$ busca entender las fuentes burocráticas e internas de la toma de decisiones e implementación de la política exterior y permite enfatizar los aspectos prácticos que explican sus alcances y límites.

${ }^{1}$ Robert Jackson y Georg Sørensen, Introduction to international relations: theories and approaches, Oxford, University Press, 2016.

2 Eugene Bardach y Erick M. Patashnik, A practical guide for policy analysis: The eightfold path to more effective problem solving, Thousand Oaks, CK Press, 2015.

${ }^{3}$ Chris Alden y Amnon Aran, Foreign policy analysis: new approaches, Nueva York, Routledge, 2016. 
La política consular de México tiene una pertinencia mundial, pero sus principales objetivos, la concentración de sus recursos y su orientación fundamental responden a las problemáticas de la relación de México con Estados Unidos, de ahí el enfoque geográfico de este artículo.

Tres son las preguntas de investigación que se busca responder. ¿Por qué México tiene una política consular caracterizada por su modelo de provisión de servicios, sus principales y específicos modos de operar, y por qué con los programas que se han desarrollado? ¿En qué medida la política consular responde a las prioridades cambiantes del gobierno en turno? ¿Qué tan efectiva es y cuáles son sus límites?

El principal hallazgo del estudio es que la política consular de México es una política pública de Estado que responde a problemas y oportunidades estructurales de la relación entre México y Estados Unidos y que demuestra una sólida continuidad a lo largo de los últimos sexenios. Su línea directriz ha sido la paulatina modernización de programas y servicios, y la inversión en la expansión de la red consular. Como dominio con un importante contenido técnico, la política consular se mantiene parcialmente aislada de decisiones estrictamente políticas y en ella tienden a predominar criterios especializados en muchas de las decisiones.

El artículo está estructurado en tres secciones, además de esta introducción. La primera se concentra en definir la naturaleza del problema de política pública que resuelve la política consular mexicana. La segunda sección se enfoca en describir la evolución de la política pública consular en el sexenio de Enrique Peña Nieto, con énfasis en continuidades y discontinuidades. En la tercera sección se concluye y se presentan recomendaciones generales para el futuro de la política consular. 


\section{DEFINICIÓN DE LOS PROBlemas DE POLÍTICA PÚBLICA QUE DEBE ABORDAR LA POLÍTICA CONSULAR}

La política consular de México puede entenderse como una respuesta a problemas y oportunidades de incumbencia del Estado. Bardach y Patashnik ${ }^{4}$ definen las políticas públicas como el conjunto de medidas tomadas para la solución de un problema o para el aprovechamiento de una oportunidad en el dominio legítimo de la acción pública. En este sentido, la política consular se propone resolver, o por lo menos administrar, los problemas que enfrentan el país y sus ciudadanos en terceros países. Adicionalmente, tiene como cometido aprovechar las oportunidades que pudieran beneficiar los intereses nacionales y de sus ciudadanos.

El fenómeno estructural subyacente en las problemáticas de la política consular es la magnitud de la población mexicana en Estados Unidos y su creciente dispersión geográfica. Este tamaño tiene sus orígenes en los cambios producidos por la promulgación en aquel país de la Ley de Reforma y Control de Inmigración de 1986 (IRCA, por sus siglas en inglés), en la brecha entre el crecimiento de la economía estadounidense y la mexicana, que generó un fuerte efecto imán, ${ }^{5}$ y en la política migratoria y de control fronterizo más restrictivo de Estados Unidos, que prácticamente eliminó la circularidad de la migración mexicana. ${ }^{6}$ Estos factores provocaron una migración neta de 9.6 millones de mexicanos entre 1990 y $2009,{ }^{7}$ que se fueron estableciendo según patrones estables

${ }^{4}$ E. Bardach y E. M. Patashnik, op. cit.

${ }^{5}$ Gordon H. Hanson, The Economic Logic of Illegal Immigration, Nueva York, Council on Foreign Relations, 2007.

${ }^{6}$ Rubén Hernández-León y Víctor Zúñiga, "Introduction to the Special Issue: Contemporary Return Migration from the United States to Mexico - Focus on Children, Youth, Schools and Families", Mexican Studies/Estudios Mexicanos, vol. 32, núm. 2 (2016), pp. 171-181.

${ }^{7}$ United States Census Bureau, American Fact Finder (base de datos en línea), 2015, https://www.census.gov/ 
y redes de migración. ${ }^{8}$ Las tendencias económicas y demográficas de Estados Unidos, como el crecimiento de la población en el sur (Carolina del Norte y del Sur, Georgia, Florida, Alabama, Arkansas) o en el noroeste del país (Washington, Oregon y, en menor medida, Utah y Idaho), produjeron una notable dispersión de la población mexicana fuera de los centros históricos de migración. ${ }^{9}$

En consecuencia, la Secretaría de Relaciones Exteriores (SRE) de México tiene que brindar servicios de documentación, protección y vinculación a más de 11.6 millones de sus nacionales en EEUU, 5.4 millones de los cuales son indocumentados ${ }^{10}$ y están dispersos en todo el territorio de ese país. ${ }^{11}$

La vulnerabilidad de las poblaciones mexicanas en EEUU afecta principalmente a los indocumentados, que están sujetos a la deportación, al abuso de sus derechos laborales, a niveles de remuneración muy por debajo de otros trabajadores ${ }^{12}$

${ }^{8}$ Charles Hirschman y Douglas Massey, "Places and peoples: the new American mosaic", en Douglas S. Massey (ed.), New Faces in New Places: The Changing Geography of American Immigration, Nueva York, Russell Sage Foundation, 2008.

${ }^{9}$ Michael Francis Johnston et al., "Mexican Population Growth in New us Destinations: Testing and Developing Social Capital Theories of Migration using Census Data", Journal of Ethnic and Migration Studies, 39 (2013), pp. 1479-1505, Dor: 10.1080/1369183X.2013.815430.

10 Ana González Barrera y Jens Manuel Krogstad, "What we know about illegal immigration from Mexico", 3 de diciembre de 2018, Pew Research Center, http://www.pewresearch.org/fact-tank/2017/03/02/ what-we-know-about-illegal-immigration-from-mexico/; Jeffrey S. Passel y D’Vera Cohn, "US Unauthorized Immigrant Total Dips to Lowest Level in a Decade", Pew Research Center, Hispanic Trends (sitio de internet), 27 de noviembre de 2018, http://www.pewhispanic.org/2018/11/27/u-s-un authorized-immigrant-total-dips-to-lowest-level-in-a-decade /

${ }^{11}$ Jorge Durand et al., "The new geography of Mexican immigration", en Víctor Zúñiga y Rubén Hernández-León (eds.), New destinations: Mexican immigration in the United States, Nueva York, Russell Sage Foundation, 2005, pp. 1-20.

${ }^{12}$ Massey y Gentsch encontraron que los trabajadores indocumentados han experimentado una reducción de más de $18 \%$ en su remuneración real desde 1986; se trata de una verdadera "penalidad de la indocumenta- 
y a peores condiciones de salud, entre otros problemas. ${ }^{13}$ Estas poblaciones necesitan servicios consulares de diversa índole: protección consular en caso de detención por autoridades migratorias, asesoría legal, documentación, asesoría de salud, entre otros. $\mathrm{Al}$ haberse asentado, se han vuelto "clientes asiduos" de los consulados. ${ }^{14}$

Los objetivos estratégicos de la política consular, reflejados en la articulación formal del Plan Nacional de Desarrollo, así como en la práctica de la cancillería, responden a estos problemas y pueden enumerarse de una manera sintética: ${ }^{15}$

1. Mejorar las condiciones de vida y el goce de los derechos humanos y civiles de sus ciudadanos que viven en el exterior. Se trata de un objetivo de largo plazo para cuyo logro el gobierno de México enfrenta severos límites, pero que es un vector constante de la política consular.

2. Articular a los mexicanos que residen en el exterior en comunidades vibrantes, integradas al país anfitrión pero vinculadas con México y que, en el largo plazo, sean un elemento de soft power para el país en sus relaciones con Estados Unidos. A partir de las reformas de

ción”. Véase Douglas S. Massey y Kerstin Gentsch, "Undocumented migration to the United States and the wages of Mexican immigrants", International Migration Review, 48 (2014), pp. 482-499.

13 Entre los muchos resultados negativos que enfrentan las comunidades indocumentadas, los autores Brian, Allen y Téllez encuentran fuertes efectos nocivos en la salud mental de niños cuyos padres han sido deportados. Brian Cisneros, Erika M. Cisneros y Alexandra Téllez, "The children left behind: The impact of parental deportation on mental health", Journal of Child and Family Studies, 24, núm. 2 (2013), pp. 386-392.

${ }^{14}$ Jeffrey Passel et al., "As growth stalls, unauthorized immigrant population becomes more settled", Pew Research Center, Hispanic Trends (sitio de internet) 3 de septiembre de 2014, http://www.pewhispanic. org/2014/09/03/as-growth-stalls-unauthorized-immigrant-populationbecomes-more-settled/

${ }^{15}$ La exposición de los objetivos se basa en documentos oficiales y en una serie de entrevistas con quienes han conducido esta política entre 2012 y 2018. 
1998, que permiten la doble nacionalidad, ${ }^{16}$ se reconoce la permanencia de la diáspora mexicana en, y su integración a, Estados Unidos.

3. Propiciar los intercambios entre México y el resto del mundo en términos de visitantes, inversiones, cultura y comercio.

4. Construir una relación integral, a nivel nacional, regional y local, entre México y Estados Unidos que contribuya a la relación estratégica con ese país.

Estos objetivos han llevado a México a articular una política consular con rasgos propios que la diferencian de las de otros países. En efecto, México ha adoptado un modelo de atención y servicio de proximidad a sus comunidades en el exterior mediante la construcción de la más amplia red de representaciones consulares de un país en otro. Sus cincuenta oficinas en EEUU establecen una presencia del Estado mexicano en la proximidad de todos los principales centros de población mexicana en territorio estadounidense.

Por otra parte, México ha desarrollado mecanismos y programas innovadores que estiran la liga del papel tradicional de los consulados. Hernández Joseph reconoce que el derecho internacional consuetudinario "no prevé como protección consular algunos de los temas que son parte de la actividad de la cancillería mexicana por medio de sus embajadas y consulados para vincularse con sus diásporas". ${ }^{17}$ Los consulados mexicanos no sólo emiten documentos, atienden a nacionales con problemas frente a las autoridades del país anfitrión y promueven la cultura y los negocios, sino que se ocupan de mejorar la salud de sus ciudadanos, de promover sus derechos laborales, de generar educación financiera, de dar apoyo en casos de violencia doméstica, de inscribir en el

${ }^{16}$ Ley de Nacionalidad, Diario Oficial de la Federación, 23 de abril de 2012, http:/ / www.diputados.gob.mx/LeyesBiblio/pdf/53.pdf

17 Daniel Hernández Joseph, Protección consular mexicana, México, Porrúa, 2015. 
Registro Civil a aquellos que nunca lo hicieron en México, de repatriar sus restos cuando fallecen, de organizar a sus comunidades, entre otras tareas que no son práctica común de otros países. ${ }^{18}$ Para México la política consular es parte integral y medular de su política exterior y está estrechamente vinculada con la relación bilateral con su poderoso vecino.

EVOLUCIÓN DE LA POLÍTICA CONSULAR EN LA ADMINISTRACIÓN Del PResidente EnRiQue PeÑa Nieto

La política consular se maneja a partir de una estructura en la SRE que la organiza en dos direcciones generales y un órgano desconcentrado asignados a la Subsecretaría para América del Norte. La Dirección General de Servicios Consulares se ocupa de la documentación consular, la Dirección General de Protección a Mexicanos en el Exterior, de los programas de asistencia legal y protección consular, y el Instituto de los Mexicanos en el Exterior, de los vínculos con la diáspora mexicana y su articulación con instituciones y organizaciones en México. Esas tres áreas coordinan la actividad de los consulados y secciones consulares mexicanas en el mundo. El abrumador peso de Estados Unidos en la actividad consular de México se refleja en la asignación de esas áreas a la Subsecretaría para América del Norte. Aunque la política consular reviste rasgos cada vez más integrales, estudiarla a lo largo de estos tres ejes refleja de manera adecuada los cortes naturales de su actividad.

\section{La política de protección a mexicanos en el exterior}

En los últimos doce años, la protección de los mexicanos en el exterior ha tenido una evolución continua en tanto que ha

18 Alexandra Délano, "The diffusion of diaspora engagement policies: A Latin American agenda”, Political Geography, 41 (2014), pp. 90-100. 
fortalecido el concepto de protección preventiva y la mayor integración de servicios. La idea de la protección preventi$\mathrm{va}^{19}$ descansa sobre la premisa de que si se puede prevenir la necesidad de llevar a cabo acciones de protección ex post, mediante campañas de información y educación, alianzas con otros actores ya asentados en la comunidad y mecanismos de atención remota, así como un trabajo político para generar mejores condiciones locales para la vida diaria de los mexicanos, se potencia la eficacia de la red consular y de sus limitados recursos. ¿Cuáles son las estrategias que mejor ilustran los esfuerzos por generar herramientas que favorezcan la protección preventiva y la capacidad de atención masiva?

El Centro de Información y Asistencia a Mexicanos (CIAM) ${ }^{20}$ -que fue una respuesta a la legislación antiinmigrante SB 1070 en Arizona ${ }^{21}$ en 2010- se ha convertido en un centro de atención telefónico con cobertura en toda Norteamérica y ha experimentado un fuerte crecimiento en cuanto al número de llamadas atendidas (véase el cuadro 1). Sin embargo, se trata aún de un número relativamente bajo, dado el tamaño de la población que potencialmente podría utilizar el servicio. ${ }^{22}$ El ciam se convierte, a partir de 2017, en el principal punto de contacto para que los mexicanos interactúen con

${ }^{19}$ La definición y algunos ejemplos de programas específicos de protección preventiva de la cancillería pueden encontrarse en Secretaría de Relaciones Exteriores, SRE, "Protección preventiva", 30 de julio de 2015, https:// www.gob.mx/sre/acciones-y-programas/proteccion-preventiva-8286

${ }^{20}$ Los servicios del ciam se describen en el siguiente micrositio: "Centro de Información y Asistencia a Mexicanos”, https://www.gob.mx/ciam

${ }^{21}$ La ley SB 1070 de Arizona alude a la norma que llevó el nombre Support Our Law Enforcement and Safe Neighborhoods Act, aprobada en 2010 en dicho estado (oficialmente se la referenció como Arizona Senate Bill 1070). Esta legislación estipuló políticas agresivas para perseguir a migrantes indocumentados, por lo que generó controversia y repudio de diferentes organizaciones.

22 Aunque en años anteriores la mayoría de las llamadas eran sobre solicitudes de protección, en 2017 fueron más las relacionadas con temas de documentación, quizás un efecto del desbordamiento del centro de llamadas Mexitel en ese año. 
las áreas de protección de los consulados. El nuevo modelo de atención es centralizado, pero tiene un componente multinivel que permite conservar la especificidad y la calidad de la atención, ya que cuando es necesario, los casos se canalizan a consulados en particular. ${ }^{23}$

\section{Cuadro 1}

Llamadas atendidas por el CIAM, por categoría de información solicitada (2014-2017)

\begin{tabular}{lrrrr}
\hline Información solicitada (resumen) & 2014 & 2015 & 2016 & \multicolumn{1}{c}{2017} \\
\hline Crimen de odio & & & 7 & 3 \\
Denuncia de fraude & 8 & 8 & 31 & 20 \\
Datos de abogados & 87 & 86 & 572 & 1036 \\
INE & & & 2458 & 1373 \\
Temas migratorios & 1991 & 647 & 1436 & 6280 \\
Información sobre doble nacionalidad & & & 3465 & 12123 \\
Otro & 4753 & 4469 & 24256 & 16455 \\
Documentación & 15542 & 14408 & 52373 & 95246 \\
Protección & 52631 & 42520 & 76609 & 53911 \\
\hline Total & 75012 & 62138 & 161207 & 186447 \\
\hline
\end{tabular}

Fuente: elaboración propia con datos del Sistema Integral de Protección Consular.

La administración de Peña Nieto continuó con la estrategia de crear redes de organizaciones aliadas de los consulados, en su mayoría de la sociedad civil, para estructurar programas y ampliar los canales de atención. ${ }^{24}$ El Programa de Asistencia Jurídica a través de Asesorías Legales Externas (PALE) ha logrado crear una red de asesores legales que atienden a mexicanos referidos por los consulados. Este programa brinda atención a aproximadamente 80000 casos al

${ }^{23}$ Héctor Cárdenas Suárez, entrevista con Jacob Prado, embajador y director general de Protección a Mexicanos en el Exterior, 11 de julio de 2018.

${ }^{24}$ Esta estrategia de apoyarse en redes de actores locales la siguen tanto las áreas de protección como el IME. 
año y en él participan más de 2600 profesionistas. ${ }^{25}$ Otro ejemplo es la creación, en 2013, del Mexican Civil Rights Advisory Group, que reúne a asociaciones civiles estadounidenses que pugnan por los derechos civiles de los mexicanos (la Mexican American Legal Defense and Educational Fund y el Northeast Independent Living Program, entre otras) y cuya función esencial es iniciar defensas colectivas de casos identificados por los consulados. ${ }^{26}$

La cancillería se propuso fortalecer la capacidad técnica de sus funcionarios de protección para atender a poblaciones con necesidades específicas (víctimas de trata, niños y niñas migrantes no acompañadas, etc.) con base en protocolos formales desarrollados por expertos nacionales e internacionales. El Protocolo para la Atención Consular de Niñas, Niños y Adolescentes Migrantes no Acompañados ${ }^{27}$ fue elaborado en colaboración con el Fondo de las Naciones Unidas para la Infancia (UNICEF) y respondió a la grave crisis que se produjo entre 2012 y $2016 .{ }^{28}$ La innovación estriba en el esfuerzo por codificar, basándose en las mejores prácticas internacionales y evidencia científica, un modo de actuación y convertir esto en práctica generalizada en los consulados.

25 "Personas mexicanas fallecidas en el extranjero: repatriación de cadáveres", Datos abiertos (sitio de internet), Gobierno de México, https://datos.gob.mx/busca/dataset/personas-mexicanas-fallecidas-enel-extranjero-repatriacion-de-cadaveres

${ }^{26}$ H. Cárdenas Suárez, entrevista con Jacob Prado, op. cit.

${ }^{27}$ El protocolo está disponible en Secretaría de Relaciones Exteriores, SRE, "Protocolo para la atención consular de niñas niños y adolescentes migrantes no acompañados", 18 de octubre de 2018, https://www. gob.mx/sre/documentos/protocolo-para-la-atencion-consular-de-ninasninos-y-adolescentes-migrantes-no-acompanados-13061

${ }^{28}$ En el lustro de 2012 a 2016, el número de niños, niñas y adolescentes no acompañados repatriados en la frontera sur de Estados Unidos sumó más de 66000, con un pico en 2013 de 16000. A partir de 2017, este número se redujo a aproximadamente 6500 por año. Véase "Atención a población vulnerable: Niñas, niños y adolescentes no acompañados atendidos por la red consular de México en EuA", Datos abiertos. Gobierno de la República (sitio de internet) https://datos.gob.mx/busca/dataset/atencion-a-poblacion-vul nerable-ninas-ninos-y-adolescentes-no-acompanados-atendidos-por-la-red- 
El Programa de Asistencia Jurídica a Casos de Pena Capital en Estados Unidos (MCLAP, por sus siglas en inglés), que dio inicio en 2000, consiste en la identificación temprana de casos susceptibles de ser castigados con la pena de muerte y su seguimiento por un grupo de abogados estadounidenses especialistas en el tema, con fondeo del gobierno de México. ${ }^{29} \mathrm{El}$ objetivo es evitar la imposición de la pena capital; su reversión, si ya se impuso, o la postergación de su aplicación. Este programa ha tenido un extraordinario éxito al evitar o revertir las ejecuciones en $89 \%$ de los 1167 casos en los que ha intervenido desde el año 2000, especialmente tomando en cuenta que se estima que sin su intervención la tasa de éxito hubiera sido menor a cinco por ciento..$^{30}$

Con la elección de Donald Trump a la presidencia de EEUU, el gobierno de México decidió reforzar la protección consular. El gobierno asignó un presupuesto extraordinario de 1000 millones de pesos en 2017 mediante la estrategia denominada Fortalecimiento para la atención de mexicanos en Estados Unidos (FAMEU). Estos recursos se destinaron principalmente a la creación de "centros de defensoría" en los consulados ( $43 \%$ del presupuesto devengado) y a la creación de 320 plazas temporales para apoyar las labores consulares (22\% del presupuesto proyectado). Los centros de defensoría coordinan e integran actividades que ya llevaban a cabo las áreas de protección, aunque con un enfoque más integral y con mayores recursos. Se trató de una evolución, más que de una ruptura con las prácticas vigentes.

Las áreas de protección realizan una labor titánica pero, a pesar de los esfuerzos por mejorar, modernizar e innovar en los servicios que se ofrecen, desde hace ya varios años el número de casos atendidos, excepto en el ámbito migratorio, se ha mantenido relativamente estable (véase la gráfica 1). Esto apunta a que la red consular no está logrando ampliar su cobertura y llegar a un porcentaje más amplio de la población.

${ }^{29}$ D. Hernández, op. cit.

${ }^{30}$ H. Cárdenas Suárez, entrevista con Jacob Prado, op. cit. 


\section{Cuadro 2}

\section{Distribución general de los recursos de la asignación extraordinaria de 1000 millones de pesos en 2017 (en dólares de EEuU)}

\begin{tabular}{|c|c|c|c|c|}
\hline Rubro & $\begin{array}{l}\text { Presupuesto } \\
\text { proyectado }\end{array}$ & $\begin{array}{c}\text { Ejercicio } \\
\text { acumulado a } \\
\text { diciembre } 2017\end{array}$ & $\begin{array}{l}\text { Desviación } \\
\text { porcentual entre } \\
\text { lo proyectado y } \\
\text { lo ejercido }\end{array}$ & $\begin{array}{l}\text { Porcentaje } \\
\text { del total } \\
\text { ejercido }\end{array}$ \\
\hline Recursos humanos (III) & 9492382 & 8602083 & $-9.38 \%$ & $22.12 \%$ \\
\hline $\begin{array}{l}\text { Programas de protección a mexicanos } \\
\text { en el exterior }\end{array}$ & 36412076 & 22785443 & $-37.42 \%$ & $58.60 \%$ \\
\hline $\begin{array}{l}\text { Fortalecimiento del Centro de } \\
\text { Información y Asistencia a Mexicanos } \\
\text { (CIAM) }\end{array}$ & 329596 & 93670 & $-71.58 \%$ & $0.24 \%$ \\
\hline $\begin{array}{l}\text { Centros de defensoría - Orientación y } \\
\text { representación legal (IV) }\end{array}$ & 15622476 & 8586338 & $-45.04 \%$ & $22.08 \%$ \\
\hline $\begin{array}{l}\text { Centros de defensoría - Talleres } \\
\text { informativos (Conoce tus Derechos, } \\
\text { Diagnóstico Migratorio, Plan de } \\
\text { Emergencia y Promoción de la Doble }\end{array}$ & & & & \\
\hline Nacionalidad) & 8564502 & 7890785 & $-7.87 \%$ & $20.29 \%$ \\
\hline Centros de defensoría - Operación & 4613524 & 592123 & $-87.17 \%$ & $1.52 \%$ \\
\hline $\begin{array}{l}\text { Reforzamiento de capacidades y } \\
\text { encuentros con autoridades y aliados } \\
\text { estratégicos (V) }\end{array}$ & 752797 & 622527 & $-17.30 \%$ & $1.60 \%$ \\
\hline $\begin{array}{l}\text { Difusión de materiales sobre } \\
\text { protección preventiva para las personas } \\
\text { mexicanas en Estados Unidos. }\end{array}$ & 6478419 & 5000000 & $-22.82 \%$ & $12.86 \%$ \\
\hline $\begin{array}{l}\text { Ayuda de emergencia a mexicanos por } \\
\text { desastres naturales FAMEU (VI) }\end{array}$ & 50761 & - & $-100.00 \%$ & $0.00 \%$ \\
\hline Programas de servicios consulares & 2741125 & 2851491 & $4.03 \%$ & $7.33 \%$ \\
\hline $\begin{array}{l}\text { Protección a mexicanos alejados de la } \\
\text { sede/consulados móviles en cuatro } \\
\text { modalidades }\end{array}$ & 1725896 & 1778530 & $3.05 \%$ & $4.57 \%$ \\
\hline Consulados móviles & 622588 & 645615 & $3.70 \%$ & $1.66 \%$ \\
\hline Consulados sobre ruedas & 942492 & 971235 & $3.05 \%$ & $2.50 \%$ \\
\hline $\begin{array}{l}\text { Jornadas sabatinas, dominicales o en } \\
\text { días inhábiles }\end{array}$ & 156895 & 161680 & $3.05 \%$ & $0.42 \%$ \\
\hline $\begin{array}{l}\text { Actividades de documentación entre } \\
\text { semana fuera de la sede consular }\end{array}$ & 3920 & - & $-100.00 \%$ & $0.00 \%$ \\
\hline
\end{tabular}




\section{Cuadro 2 conclusión}

\begin{tabular}{|c|c|c|c|c|}
\hline Rubro & $\begin{array}{l}\text { Presupuesto } \\
\text { proyectado }\end{array}$ & $\begin{array}{c}\text { Ejercicio } \\
\text { acumulado a } \\
\text { diciembre } 2017\end{array}$ & $\begin{array}{l}\text { Desviación } \\
\text { porcentual entre } \\
\text { lo proyectado y } \\
\text { lo ejercido }\end{array}$ & $\begin{array}{l}\text { Porcentaje } \\
\text { del total } \\
\text { ejercido }\end{array}$ \\
\hline $\begin{array}{l}\text { Call center de documentación y } \\
\text { protección Mexitel (pago en México) }\end{array}$ & 1015228 & 1072961 & $5.69 \%$ & $2.76 \%$ \\
\hline $\begin{array}{l}\text { Programas de protección al patrimonio } \\
\text { - Ventanillas de asesoría financiera }\end{array}$ & 2588832 & 2764041 & $6.77 \%$ & $7.11 \%$ \\
\hline $\begin{array}{l}\text { Talleres de capacitación Protección al } \\
\text { patrimonio "Más Vale Estar Preparado" }\end{array}$ & 451777 & 473571 & $4.82 \%$ & $1.22 \%$ \\
\hline $\begin{array}{l}\text { Apoyo para asesoría y educación } \\
\text { financiera en plazas comunitarias } \\
\text { (economía familiar) }\end{array}$ & 557107 & 587224 & $5.41 \%$ & $1.51 \%$ \\
\hline $\begin{array}{l}\text { Apoyo para mentorías de alfabetización } \\
\text { financiera y emprendimiento en } \\
\text { organizaciones de migrantes }\end{array}$ & 557107 & 595597 & $6.91 \%$ & $1.53 \%$ \\
\hline $\begin{array}{l}\text { Actividad o evento de finanzas en } \\
\text { ventanillas de salud y consulados } \\
\text { móviles (feria, taller, conferencia, foro, } \\
\text { otros) }\end{array}$ & 551066 & 601712 & $9.19 \%$ & $1.55 \%$ \\
\hline $\begin{array}{l}\text { Operación VAF, materiales, } \\
\text { distribución, encuentros }\end{array}$ & 471777 & 505937 & $7.24 \%$ & $1.30 \%$ \\
\hline $\begin{array}{l}\text { Apoyo a migrantes a través de las } \\
\text { delegaciones }\end{array}$ & 3082795 & 1880153 & $-39.01 \%$ & $4.84 \%$ \\
\hline Equipamiento y promoción (VII) & 3082795 & 1880153 & $-39.01 \%$ & $4.84 \%$ \\
\hline Total de recursos & 54317210 & 38883210 & $-28.41 \%$ & $100.00 \%$ \\
\hline
\end{tabular}

Fuente: elaboración propia con base en datos del portal de transparencia de Protección a Mexicanos en el Exterior de la SRE, https://trans parenciaproteccion.sre.gob.mx/pdfs/presupuestos/56_1516150984.pdf 


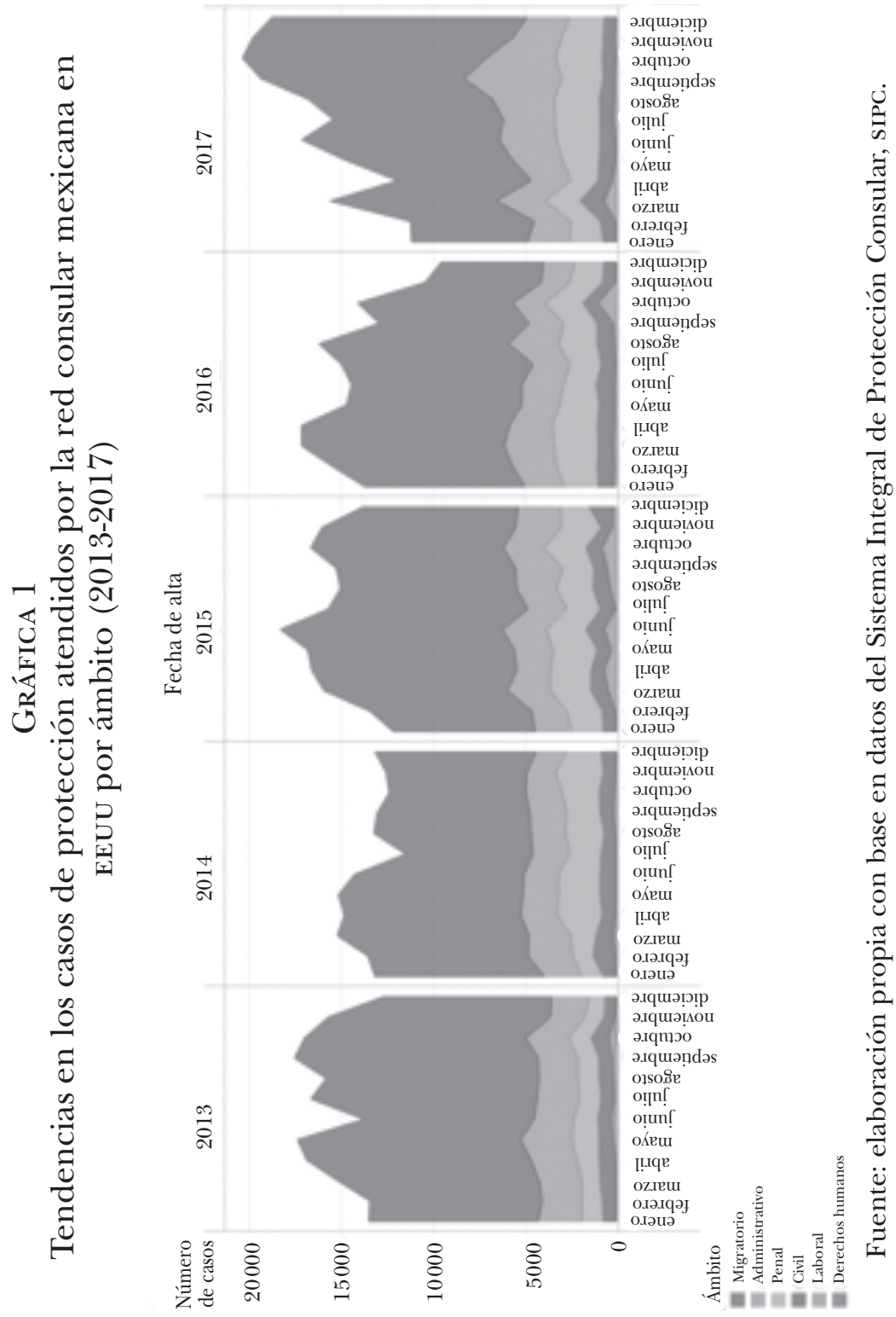


El estudio realizado en 2017 por el Centro de Investigación y Docencia Económicas (CIDE) para la Dirección General de Protección concluye que la calidad de la protección consular difícilmente puede ser pareja cuando existen disparidades inmensas en el número de casos atendidos por empleado. En efecto, mientras que el promedio de la red consular es de 33 casos por empleado al mes, en las representaciones de frontera cada empleado atiende entre $65 \mathrm{y}$ 173 casos. Un mexicano que recibe atención en un consulado fronterizo tendrá una entrevista mucho más breve y una intervención mucho más superficial que alguien en Chicago, San Francisco o Nueva York. Estas conclusiones coinciden con las de Hernández Joseph ${ }^{31}$ en el sentido de que es necesario darle un mayor énfasis a la calidad de la atención, lo que depende, por supuesto, de contar con mejores instrumentos, más recursos financieros y recursos humanos altamente calificados.

En conclusión, el sexenio 2012-2018 se caracterizó por la consolidación de la política de protección, anclada en la provisión de servicios directos a la población mexicana en EEUU, pero fortalecida por una estrategia de protección preventiva, por la expansión y profundización de redes de apoyo a través de organizaciones de la sociedad civil locales y de la modernización e innovación en los modelos de atención. Hacia el final del sexenio de Peña Nieto, la SRE respondió al reto de la era Trump mediante una inyección de gasto para integrar, consolidar y ampliar las acciones de protección. Sin embargo, se advierte que la red consular está llegando a un punto de saturación que afecta la calidad de la atención y que es necesario encontrar formas de llegar a un más alto porcentaje de su población objetivo.

${ }^{31}$ D. Hernández, op. cit. 
La estrategia en materia de servicios consulares

Los servicios consulares consisten en la emisión de documentos oficiales fuera del territorio del país tanto para nacionales como extranjeros. La mayor parte de estos documentos son pasaportes, matrículas consulares y documentos del Registro Civil otorgados a mexicanos y visas para extranjeros. ${ }^{32}$ Entre enero de 2013 y julio de 2018 se han emitido más de 14 millones de documentos (véase el cuadro 3), con un pico anual en 2015 resultado del programa Deferred Action for Parents of Americans.

\section{Cuadro 3}

Producción de documentos por servicios consulares selectos

\begin{tabular}{|c|c|c|c|c|c|c|c|}
\hline Servicio & 2013 & 2014 & 2015 & 2016 & 2017 & $\begin{array}{c}2018 \\
\text { enero - agosto }\end{array}$ & $\begin{array}{c}\text { Total } \\
2013-2018\end{array}$ \\
\hline $\begin{array}{l}\text { Pasaportes } \\
\text { Matrículas }\end{array}$ & 1028629 & 1200281 & 1416027 & 1117906 & 1168088 & 839778 & 6770709 \\
\hline consulares & 961563 & 967820 & 1127124 & 827491 & 840386 & 563451 & 5287835 \\
\hline $\begin{array}{l}\text { Visas } \\
\text { Actas de } \\
\text { Registro }\end{array}$ & 142803 & 144883 & 144003 & 157738 & 154436 & 108945 & 852808 \\
\hline $\begin{array}{l}\text { Civil } \\
\text { Servicios }\end{array}$ & 130500 & 124156 & 272682 & 341764 & 341764 & 321312 & 1532178 \\
\hline $\begin{array}{l}\text { notariales } \\
\text { Solicitud de }\end{array}$ & 44730 & 44834 & 45828 & 40568 & 46025 & 33443 & 255428 \\
\hline $\begin{array}{l}\text { trámite INE } \\
\text { Otros }\end{array}$ & - & & ـ & 215871 & 324927 & 245038 & 785836 \\
\hline servicios & 9169 & 115118 & 113053 & 106215 & 105084 & 66192 & 514831 \\
\hline Total & 2319407 & 2599106 & 3120732 & 2809569 & 2982727 & 2178159 & 16009700 \\
\hline
\end{tabular}

Fuente: elaboración propia con base en datos de la SRE.

32 En Estados Unidos la gran mayoría de los documentos son emitidos a mexicanos, dado que los estadounidenses no requieren visa para visitar México. 
La SRE ha resuelto el reto de emitir tan elevado número de documentos mediante un modelo de servicio de proximidad, descentralizado y basado en el uso intensivo de las tecnologías de la información. Éste se compone de la red consular de cincuenta oficinas en EEUU, el servicio de información y citas, telefónico y en línea Mexitel, la red informática centralizada Sistema Integral de Administración Consular (SIAC), la operación de miembros del Servicio Exterior Mexicano y personal auxiliar local y una garantía implícita con el público de que su documento, si es que califica, se entregará el mismo día en que acude al consulado. ${ }^{33}$

El modelo de operación no ha cambiado en su esencia desde los años ochenta, cuando se produjo una gran expansión de la red consular, pero en los últimos ocho años se han hecho grandes inversiones para su modernización e innovación, fondeadas casi exclusivamente con ingresos derivados del cobro de derechos por los servicios consulares.

Los ingresos por estos servicios se entregan a la Tesorería de la Federación y, a su vez, son devueltos parcialmente a la SRE. En 2017, de los 155 millones de dólares que se recaudaron en el exterior (véase el cuadro 4), la cancillería tuvo acceso a 2556 millones de pesos, es decir, aproximadamente el $87 \%$ del total.

Estos ingresos son adicionales a los 7819 millones de pesos asignados en el Presupuesto de Egresos de la Federación y se utilizan directamente para programas y proyectos, y para la operación de los consulados. La Dirección General de Servicios Consulares sufraga sus iniciativas de modernización e innovación con ingresos consulares, tanto en la parte correspondiente a los ingresos consulares que le están destinados, como con recursos que se erogan a través de la Dirección General de Tecnologías de Información e Innovación. En efecto,

33 Una revisión de las prácticas en esta materia de los países de la Organización para la Cooperación y el Desarrollo Económicos (OCDE) y de otros países con elevado número de migrantes (India, China y Filipinas) revela que casi todos expiden documentos fuera de su territorio mediante una combinación de servicios subrogados para la recepción de documentación, procesamiento central y entrega por correo o paquetería. 


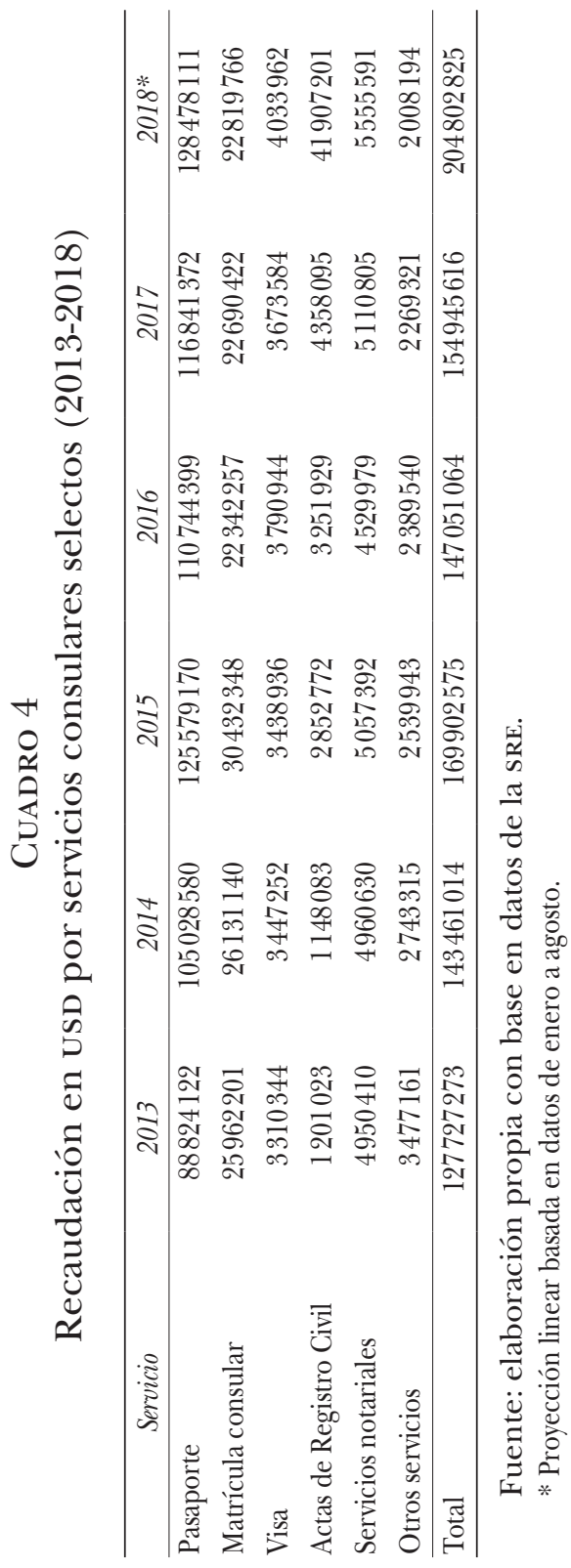


entre 2013 y 2018, la cancillería invirtió 2727 millones de pesos en proyectos de modernización de los servicios consulares, principalmente en Mexitel, el proyecto del nuevo pasaporte mexicano, las formas numeradas de alta seguridad y el desarrollo y equipamiento del SiAc, que representa la pieza clave de la estrategia de modernización e innovación (véase el cuadro 5 ).

\section{CUADro 5}

Evolución del uso de los ingresos consulares en proyectos, por año y por concepto de gasto, en millones de pesos (2013-2018)

\begin{tabular}{|c|c|c|c|c|c|c|c|}
\hline \multirow[b]{2}{*}{ Concepto de gasto } & \multicolumn{6}{|c|}{ Año } & \multirow[b]{2}{*}{ Total } \\
\hline & 2013 & 2014 & 2015 & 2016 & 2017 & 2018 & \\
\hline Proyectos de servicios consulares & 118.2 & 283.1 & 221.7 & 139.5 & 126 & 223.8 & 1112.3 \\
\hline Mexitel & 57.7 & 81 & 90 & 65 & 67.6 & 117.2 & 478.5 \\
\hline Consulados móviles & 15 & 3.5 & 4.2 & 4.1 & 4.4 & 5.5 & 36.7 \\
\hline Formas numeradas & 18 & 75.3 & 90 & 47 & 47 & 93.6 & 370.9 \\
\hline $\begin{array}{l}\text { Estándares de atención al público } \\
\text { (colaboración CIDE-SRE) }\end{array}$ & 7.5 & 14 & 14.5 & 14.5 & 0 & 0 & 50.5 \\
\hline Consulados sobre ruedas & 8 & 27 & 10 & 3.9 & 3.5 & 4.5 & 56.9 \\
\hline Aula virtual de capacitación consular & 5.5 & 0 & 2.9 & 0 & 0 & 0 & 8.4 \\
\hline $\begin{array}{l}\text { Programa de comisiones informáticos } \\
\text { regionales }\end{array}$ & 0 & 0 & 0 & 1.2 & 0 & 0 & 1.2 \\
\hline Otros proyectos varios & 2.5 & 6 & 4.5 & 3.8 & 3.5 & 3 & 23.3 \\
\hline Otros proyectos de ejercicios anteriores & 4 & 76.3 & 5.6 & 0 & 0 & 0 & 85.9 \\
\hline Infraestructura informática y de seguridad & 70.5 & 140.9 & 379.6 & 310.9 & 355 & 358.6 & 1615.5 \\
\hline Nuevo pasaporte mexicano & 0 & 0 & 80 & 187.6 & 195.5 & 200 & 663.1 \\
\hline $\begin{array}{l}\text { Red Multi Protocol Label Switching } \\
\text { (MPLS) Norteamérica }\end{array}$ & 0 & 0 & 23.3 & 0 & 0 & 5 & 28.3 \\
\hline Servicios de desarrollo, mantenimiento & & & & & & & \\
\hline y soporte SIAC & 0 & 0 & 40 & 54 & 60.7 & 70.5 & 225.2 \\
\hline Equipamiento para el SIAC & 1 & 5 & 19.4 & 14.9 & 11.4 & 20.7 & 72.4 \\
\hline $\begin{array}{l}\text { Equipamiento para representaciones } \\
\text { en el exterior }\end{array}$ & 30 & 11 & 86.6 & 54.4 & 87.4 & 60.9 & 330.3 \\
\hline $\begin{array}{l}\text { Programa de comisiones informáticas } \\
\text { regionales }\end{array}$ & 9 & 5 & 6 & 0 & 0 & 1.5 & 21.5 \\
\hline Otros proyectos de ejercicios anteriores & 30.5 & 119.9 & 124.3 & 0 & 0 & 0 & 274.7 \\
\hline
\end{tabular}
Total $\begin{array}{lllllll}188.7 & 424 & 601.3 & 450.4 & 481 & 582.4 & 2727.8\end{array}$ Fuente: elaboración propia con base en datos de la SRE. 
Los datos apuntan a una preocupante tendencia al alza del gasto en operación frente a lo que está disponible para proyectos, lo que puede vulnerar la capacidad de la cancillería de seguir invirtiendo en estos procesos de modernización.

\section{Cuadro 6}

Evolución del uso de los ingresos consulares por año y por concepto de gasto, en millones de pesos (2013-2018)

\begin{tabular}{|c|c|c|c|c|c|c|c|}
\hline & \multicolumn{6}{|c|}{ Año } & \multirow{2}{*}{$\frac{\text { Variación }}{\text { porcentual }}$} \\
\hline Concepto de gasto & 2013 & 2014 & 2015 & 2016 & 2017 & 2018 & \\
\hline Gastos fijos & 1114.3 & 1157.3 & 1498.9 & 1801.3 & 1892.9 & 1683.4 & $51 \%$ \\
\hline $\begin{array}{l}\text { Gastos de operación de } \\
\text { consulados }\end{array}$ & 1029.3 & 1107.3 & 1365.1 & 1631.3 & 1720.4 & 1683.4 & $64 \%$ \\
\hline $\begin{array}{l}\text { Programa de Asistencia } \\
\text { Jurídica a Casos de Pena }\end{array}$ & & & & & & & \\
\hline Capital en EEUU & 85 & 50 & 78.8 & 80.9 & 100.5 & 0 & $-100 \%$ \\
\hline Programa de Asesorías & & & & & & & \\
\hline Legales Externas en EEUU & 0 & 0 & 55 & 89.1 & 72 & 0 & \\
\hline Proyectos & 312.4 & 710.6 & 927.4 & 712.3 & 663.4 & 894.8 & $186 \%$ \\
\hline Protección consular & 5.5 & 71.6 & 24.5 & 0.2 & 0 & 0 & $-100 \%$ \\
\hline Servicios consulares & 118.2 & 283.1 & 221.8 & 139.5 & 126 & 223.8 & $89 \%$ \\
\hline Infraestructura & & & & & & & \\
\hline $\begin{array}{l}\text { informática y seguridad } \\
\text { Mobiliario, servicios y }\end{array}$ & 70.5 & 140.9 & 379.6 & 310.9 & 355 & 358.6 & $409 \%$ \\
\hline habilitación de inmuebles & 39 & 109.8 & 94.1 & 5 & 53.2 & 45 & $15 \%$ \\
\hline Empleados locales & 79.2 & 105.2 & 207.4 & 256.7 & 129.2 & 267.4 & $238 \%$ \\
\hline Total & 1426.7 & 1867.9 & 2426.3 & 2513.6 & 2556.3 & 2578.2 & $81 \%$ \\
\hline
\end{tabular}

Fuente: elaboración propia con base en datos de la SRE.

Han sido los rubros operativos los que han visto los incrementos más significativos en gasto (véase el cuadro 7), pasando de consumir $86 \%$ de los ingresos consulares, en 2013, a $91 \%$, en 2018. Esta tendencia apunta a un deterioro paulatino de las posibilidades de invertir en proyectos innovadores, ya que cada vez más los ingresos consulares se van en equipamiento, sueldos y operación. 


\section{Cuadro 7}

Porcentaje del gasto de los ingresos consulares por año y concepto de gasto (2013-2018)

\begin{tabular}{|c|c|c|c|c|c|c|c|}
\hline Concepto de gasto & 2013 & 2014 & 2015 & 2016 & 2017 & 2018 & Promedio \\
\hline Gastos fijos & $78 \%$ & $62 \%$ & $62 \%$ & $72 \%$ & $74 \%$ & $65 \%$ & $68 \%$ \\
\hline $\begin{array}{l}\text { Gastos de operación de } \\
\text { consulados }\end{array}$ & $72 \%$ & $59 \%$ & $56 \%$ & $65 \%$ & $67 \%$ & $65 \%$ & $64 \%$ \\
\hline $\begin{array}{l}\text { Programa de Asistencia } \\
\text { Jurídica a Casos de Pena } \\
\text { Capital en Eeuu }\end{array}$ & $6 \%$ & $3 \%$ & $3 \%$ & $3 \%$ & $4 \%$ & $0 \%$ & $3 \%$ \\
\hline $\begin{array}{l}\text { Programa de Asesorías } \\
\text { Legales Externas en EEUU }\end{array}$ & $0 \%$ & $0 \%$ & $2 \%$ & $4 \%$ & $3 \%$ & $0 \%$ & $2 \%$ \\
\hline Proyectos & $22 \%$ & $38 \%$ & $38 \%$ & $28 \%$ & $26 \%$ & $35 \%$ & $32 \%$ \\
\hline Protección consular & $0 \%$ & $4 \%$ & $1 \%$ & $0 \%$ & $0 \%$ & $0 \%$ & $1 \%$ \\
\hline Servicios consulares & $8 \%$ & $15 \%$ & $9 \%$ & $6 \%$ & $5 \%$ & $9 \%$ & $8 \%$ \\
\hline $\begin{array}{l}\text { Infraestructura informática } \\
\text { y seguridad }\end{array}$ & $5 \%$ & $8 \%$ & $16 \%$ & $12 \%$ & $14 \%$ & $14 \%$ & $12 \%$ \\
\hline $\begin{array}{l}\text { Mobiliario, servicios y } \\
\text { habilitación de inmuebles }\end{array}$ & $3 \%$ & $6 \%$ & $4 \%$ & $0 \%$ & $2 \%$ & $2 \%$ & $3 \%$ \\
\hline Empleados locales & $6 \%$ & $6 \%$ & $9 \%$ & $10 \%$ & $5 \%$ & $10 \%$ & $8 \%$ \\
\hline Total & $100 \%$ & $100 \%$ & $100 \%$ & $100 \%$ & $100 \%$ & $100 \%$ & $100 \%$ \\
\hline
\end{tabular}

Fuente: elaboración propia con base en datos de la SRE.

Como se aprecia de la revisión del gasto, la estrategia en el ámbito de los servicios consulares se ha centrado en la innovación. La embajadora Olga García Guillén explica los dos ejes de la innovación:

[...] por una parte, introducir dos nuevos servicios que han sido reclamados desde hace muchos años por la comunidad mexicana en el exterior: la expedición de copias de actas de nacimiento independientemente del lugar de registro y la credencial de elector y, por la otra, una gran revolución consular de poder sistematizar todos los servicios en un solo sistema, en una sola base de datos uniforme, homogénea con estándares e interconectada con otros servicios. ${ }^{34}$

${ }^{34}$ Héctor Cárdenas Suárez, entrevista con Olga García Guillén, embajadora y directora general de Servicios Consulares, 6 de agosto de 2018. 


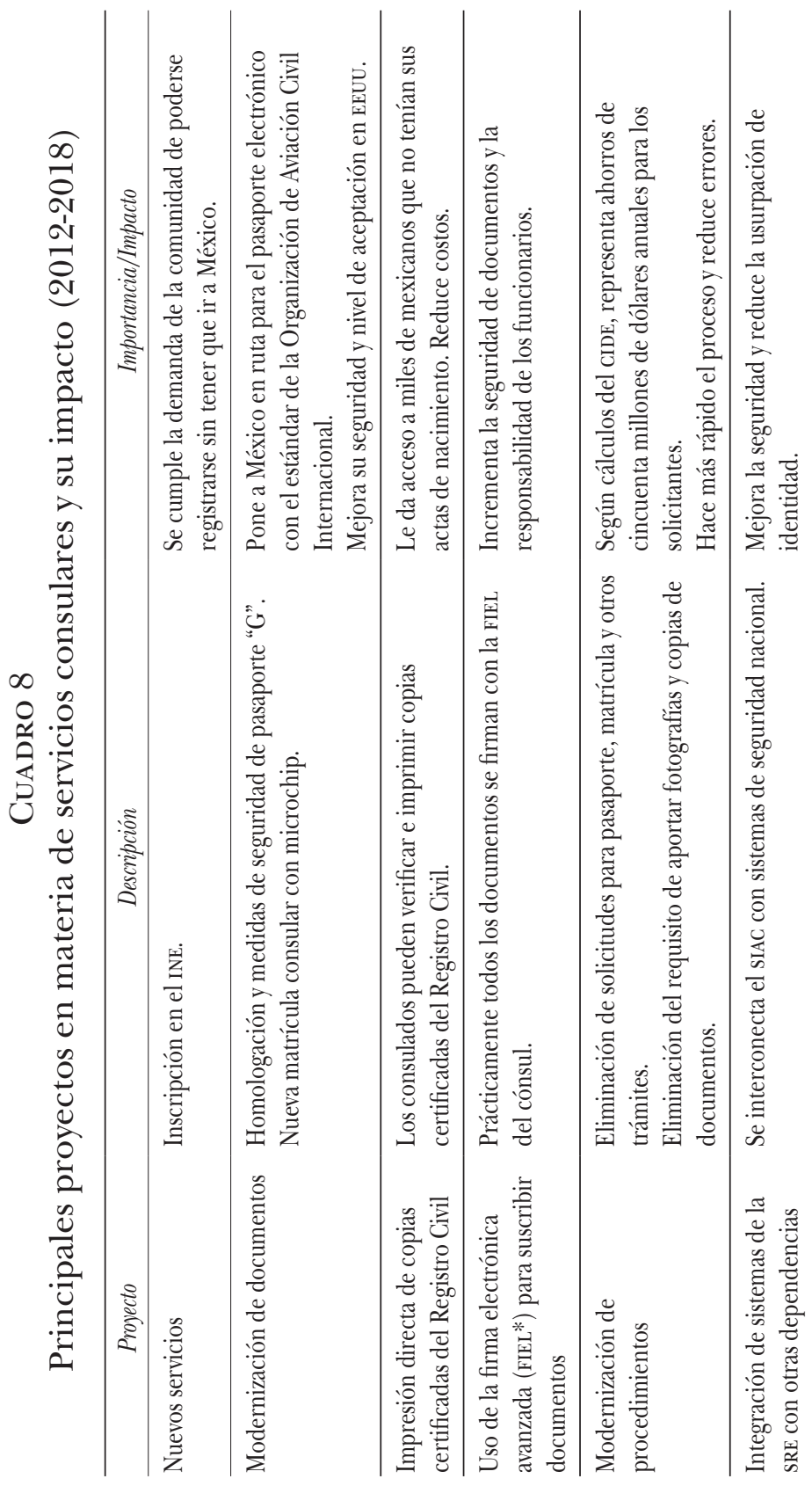




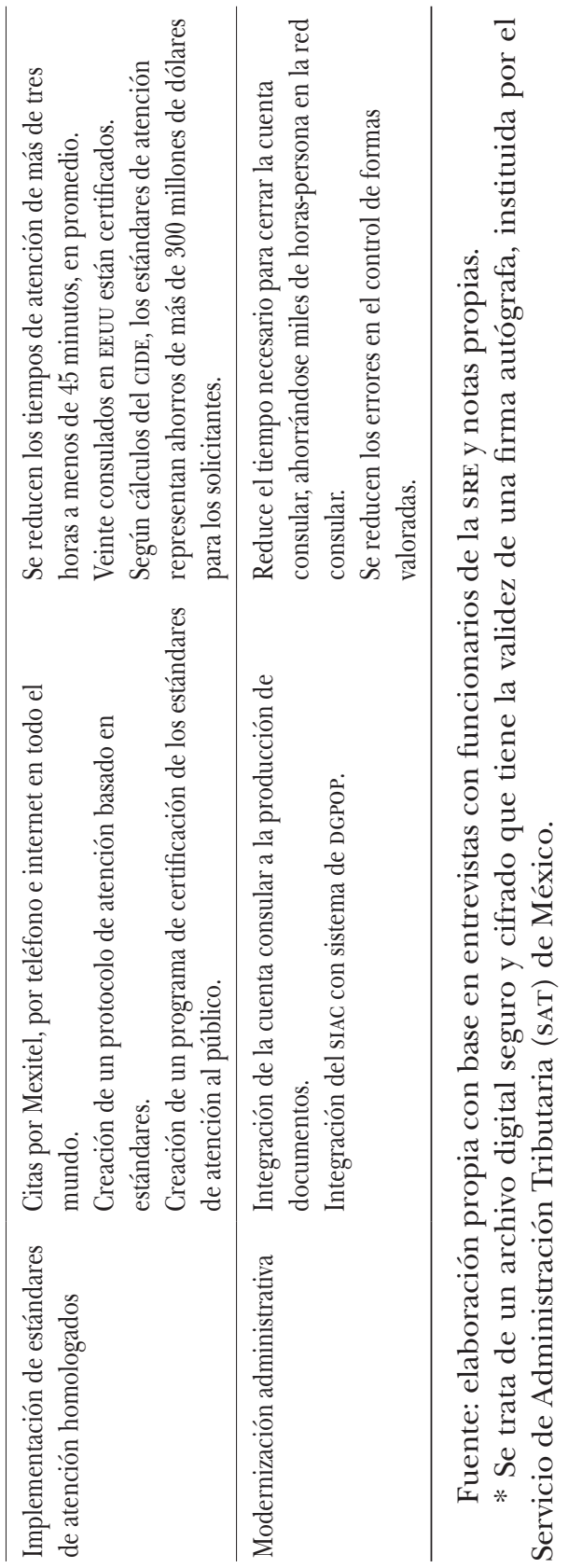


Los resultados positivos en el área de servicios consulares (véase el cuadro 8) se deben a tres factores decisivos. Primero, un enfoque estratégico, ambicioso pero gradualista, adoptado por la SRE desde el gobierno de Felipe Calderón y que siguió en el sexenio 2012-2018. La embajadora García Guillén relata que en varias ocasiones otros colegas insistían en la necesidad de abandonar el siac (que se empezó a diseñar en 2002) y empezar de cero, con un nuevo "gran" sistema. Su intuición iba en dirección contraria: abonar en lo ya construido, mejorar sin abandonar e ir consolidando un sistema estratégico para la cancillería. Segundo, una fuerte apuesta por la tecnología y la modernización de los servicios, desde el punto de vista tecnológico, normativo y de procesos. En tercer lugar, voluntad para tomar decisiones con base en evidencia, analizando los propios datos y la información de que dispone la cancillería, tanto a partir de sus sistemas como de otras fuentes públicas.

Estos resultados positivos no deben llevar a soslayar los desafíos que aún se enfrentan: dotar a México de un pasaporte electrónico que cumpla con los estándares de la OACI, modernizar los procesos de visas y ajustar el marco legal para, por ejemplo, permitir la renovación de ciertos pasaportes de bajo riesgo sin necesidad de la presencia física del solicitante. Éstos son todos retos sustantivos, técnicos, que deben enfrentarse. La problemática mayor será la disponibilidad de los recursos financieros para seguir con esta ruta de innovación.

\section{La política de vinculación con las comunidades mexicanas en el exterior}

Durante el sexenio 2012-2018, la SRE continuó su estrategia de vinculación con las comunidades mexicanas en el exterior a través del Instituto de los Mexicanos en el Exterior (IME), ${ }^{35}$

35 El Ime, creado en 2002, es descendiente del Programa de Comunidades Mexicanas en el Exterior, lanzado por Carlos Salinas entre 1989 y 
que tiene como misión "promover estrategias, integrar programas, recoger propuestas y recomendaciones de las comunidades, sus miembros, sus organizaciones y órganos consultivos, tendientes a fortalecer sus vínculos con su país de origen y a fomentar su integración en las sociedades en las que residen e interactúan". Su misión refleja un objetivo dual: por una parte, mantener los vínculos con México y, por la otra, fomentar su integración en el país anfitrión e incluso su naturalización. ${ }^{36}$

No se puede hacer una evaluación del IME sin abordar la canalización de recursos entre 2014 y 2016 a asociaciones estadounidenses como AEM-USA Foundation y Parents Alliance, vinculadas a la agrupación Juntos Podemos, presidida por Josefina Vázquez Mota. El programa de "Juntos Podemos", que implicó asignaciones presupuestales extraordinarias, ${ }^{37}$ generó atención negativa en los medios y propició varias auditorias que afectaron la imagen del instituto y de la cancillería. A pesar de la polémica, el diseño del programa como alianza con organizaciones civiles es congruente con la estrategia que ha seguido la política consular. De hecho, el programa IME Becas, que creció año con año en el sexenio de Peña Nieto y que se apoya en organizaciones locales para identificar beneficiarios y canalizar los fondos del gobierno de México, tiene un diseño similar.

El IME nació también con mucho empuje y algo de voluntarismo, a partir del cual se idearon mecanismos innovadores para generar alianzas y rendir buenos resultados a bajo costo, pero no necesariamente se prestó la debida atención a sus procesos internos. A partir del escándalo de Juntos Po-

1990, y de la Oficina para Mexicanos en el Exterior, dependiente de la presidencia de la República, creada por Vicente Fox en 2000.

${ }^{36}$ Héctor Cárdenas Suárez, entrevista con Juan Carlos Mendoza, embajador y presidente del Instituto de los Mexicanos en el Exterior, 11 de septiembre de 2018.

${ }^{37}$ Véase el artículo de Jorge Schiavón y Bruno Figueroa, "Los recursos y las capacidades de la política exterior de México (2012-2018)" en este mismo número de la revista Foro Internacional, núms. 237-238. 
demos, la institución se dedicó a poner orden en sus procedimientos. Se arreglaron problemas con la forma en que se asignaban y transferían los recursos a los consulados (ya que se utilizaba una partida presupuestal única que dificultaba la trazabilidad de los recursos), se uniformó el esquema de los memorándums de entendimiento que firman el IME y los consulados con sus socios locales y se crearon lineamientos para programas que no los tenían, entre otras medidas de higiene administrativa. En ese sentido, el instituto resultó fortalecido de este capítulo en su historia. ${ }^{38}$

El modelo de ventanillas, que ha tenido un fuerte crecimiento, destaca por su carácter tripartita, integrado por el consulado, un socio local y un socio en México. Dicho modelo se ha extendido y adaptado a distintos ámbitos y hoy el IME cuenta con ventanillas de salud, de orientación educativa y de asesoría financiera y protección al patrimonio familiar en casi todos los consulados. Al asociar actores locales especializados con los programas, se potencia la capacidad técnica y de acceso a beneficiarios que los consulados difícilmente podrían lograr. La ventanilla de asesoría financiera, por ejemplo, nace en Nueva York en 2014 por medio de una colaboración entre el Consulado General de México, la alcaldía de Nueva York y Citibank, que financió el proyecto. Posteriormente, en 2017, la ventanilla se fondea desde México con recursos de FAMEU y se establece en los consulados.

También en 2017, se estableció un consejo asesor del programa de ventanillas, de perfil técnico y directivo, integrado por especialistas destacados. Este consejo es emblemático de la dirección que toma la gobernanza del IME tras la desaparición del consejo consultivo (CCIME) integrado por miembros de las comunidades mexicanas en el exterior, que era una "asamblea coordinadora del liderazgo de la diáspora como un todo: un consejo de liderazgo formal e institucionalizado", ${ }^{39}$

${ }^{38}$ H. Cárdenas Suárez, entrevista con Juan Carlos Mendoza, op. cit.

39 David Ayón, "La política mexicana y la movilización de los migrantes mexicanos en Estados Unidos”, en Carlos González Gutiérrez (coord.), 
pero que dejó de ser funcional tras sufrir un proceso de politización. ${ }^{40} \mathrm{~A}$ fin de que el modelo de ventanillas tenga impacto, necesita crecer y salir del consulado para llegar a un público mucho más amplio que solamente aquellos que acuden físicamente a una oficina consular. ${ }^{41}$

El otro proyecto clave del ImE es el de la Red de Talentos Mexicanos, rebautizada Red Global mx, que agrupa a connacionales altamente calificados en una serie de capítulos en las principales zonas metropolitanas del mundo y los conecta a nodos, que son sus contrapartes, ubicados en distintas entidades federativas en torno a sectores prioritarios, ya sea industriales o educativos. Aunque la red se ha expandido hasta alcanzar 6500 miembros, el reto del programa ha sido generar suficientes proyectos concretos para que sus miembros puedan estar activos y trabajando en pro de México. En los últimos seis años ha habido progreso al haberse habilitado nodos en catorce estados de la República que llevan a cabo proyectos con miembros de la red.

El IME es una institución que tiene una gran variedad de programas, algunos mayores (ventanillas, ImE Becas, Red Global Mx) y otros más pequeños o tradicionales (concurso anual de dibujo infantil, fomento deportivo, vinculación con clubes de oriundos y plazas comunitarias). Cabe preguntarse si no es necesario, a 15 años de su creación, un replanteamiento de sus prioridades en aras de concentrar los recursos en un menor número de programas de probada efectividad.

Estado-diáspora: la perspectiva de América Latina y el Caribe, t. 1, México, Miguel Ángel Porrúa, pp. 113-144.

${ }^{40}$ Héctor Cárdenas Suárez, entrevista con Sergio Alcocer Martínez de Castro, exsubsecretario para América del Norte, 24 de octubre de 2018.

41 El autor realizó un cálculo, con base en datos del SIAc, de que anualmente acuden aproximadamente 1.4 millones de personas a los consulados en EEUU, respecto a una población de entre 11.5 y 12 millones de mexicanos que residen en ese país. 


\section{Innovación, integración y coordinación}

La perspectiva de silos administrativos esconde el importante nivel de coordinación que existe entre las actividades de las tres áreas. La política consular se ejecuta mediante una red de oficinas coordinadas por la Subsecretaría para América del Norte y las tres unidades administrativas que hemos mencionado (la Dirección General de Servicios Consulares, la Dirección General de Protección a Mexicanos en el Exterior y el Instituto de los Mexicanos en el Exterior). La ejecución mediante una red, la distancia física y administrativa entre los consulados y las oficinas centrales, y cierta autonomía tradicional de los titulares de las representaciones de México han hecho que la política consular se construya no sólo con iniciativas ideadas y propulsadas desde el centro, sino a partir de la práctica local de los consulados. La red consular mexicana es un laboratorio de experimentación e innovación. Muchos de los programas más relevantes que caracterizan su práctica (las ventanillas de salud, la asesoría financiera, la atención integral a víctimas de violencia doméstica, el sistema de citas para documentos, los memorándums de entendimiento, los consulados móviles y sobre ruedas, etc.) surgieron de esfuerzos de consulados específicos, que después fueron retomados por las autoridades centrales de la SRE y difundidas al resto de la red consular. Han sido los propios consulados los que han buscado fórmulas para coordinarse entre circunscripciones. Una de las iniciativas más prometedoras de la administración 2012-2018 surge de la tradición, iniciada en 2003, de los diez cónsules de California de reunirse periódicamente para intercambiar experiencias, coordinarse y colaborar. La idea dio origen a la Coordinación de Cónsules de California (CoCoCa) y fue retomada por el subsecretario para América del Norte, Sergio Alcocer, en 2014 para formar coordinaciones regionales de cónsules en EEUU, como un mecanismo para mejorar la coordinación, pero también para la inteligencia de que dispone la cancillería para actuar de manera proactiva y preventiva en todo el territorio estadounidense. 
Lograr que las mejores prácticas se propaguen en la red no siempre es fácil. Los casos exitosos se deben a que desde México se identificó la práctica y se destinó esfuerzo, capital político y recursos para extenderla. Es el caso del programa de citas y estándares para la atención al público, del modelo de ventanillas, del mecanismo de coordinación con países de Centroamérica en materia de protección (TriCaMex).$^{42}$ En cambio, otras iniciativas, como la de la creación de asociaciones con fines de advocacy, ${ }^{43}$ no se han extendido. En este último caso, quizás se deba a la renuencia de la cancillería a tener una actividad a nivel local que pudiera considerase demasiado injerencista en la política interna. Es un tema que necesita debatirse pues, si bien supone riesgos, representa una oportunidad importante para fortalecer la efectividad de México para influir en la política local. No se olvide que, como lo expresó Tip O’Neill, ${ }^{44}$ en EEUU, “toda política es política local".

\section{CONCLUSIONES Y RECOMENDACIONES PARA LA POLÍTICA CONSULAR EN LOS PRÓXIMOS SEIS AÑOS}

La política consular mexicana siguió su ruta de política de Estado durante la administración Peña Nieto, consolidándose y acelerándose algunas de las tendencias seculares que la animan. Hubo un fuerte impulso a la modernización, a la

42 Triángulo de Centroamérica y México, iniciativa que nace en McAllen y se convierte en un mecanismo de coordinación regional a nivel de cancilleres.

${ }^{43}$ Un ejemplo es el grupo Cien Amigos, fundado en Sacramento por el entonces cónsul general Carlos González Gutiérrez como organización de tipo 501(c) (4), es decir, una organización sin fines de lucro que, de acuerdo con la legislación estadounidense, está exenta del pago de impuestos sobre la renta.

${ }^{44}$ Se refiere al político estadounidense Thommas Phillips "Tip" O'Neill Jr, quien tuvo una extensa carrera legislativa en el Congreso norteamericano y se desempeñó como Speaker of the House of Representatives de 1977 a 1987. 
innovación tecnológica, a la profesionalización de su gestión y administración con algunas iniciativas novedosas y reacciones a coyunturas retadoras. Los problemas de fondo, estructurales, que subyacen y le dan razón de ser, no han cambiado y, por tanto, tampoco han cambiado en demasía las recetas para afrontarlos. Si bien la población mexicana indocumentada en EEUU se ha reducido en aproximadamente un millón y medio de personas entre 2007 y $2016,{ }^{45}$ la población objetivo de los programas que integran la política consular sigue siendo enorme: 5.4 millones de inmigrantes formales y otro tanto de indocumentados. Se trata cada vez más de una población de residencia prolongada que necesita documentos, servicios de vinculación y protección.

A pesar de los innegables éxitos de la política consular en este periodo, los recortes presupuestales de los últimos tres años del sexenio tuvieron impactos desfavorables en la operación de los programas. La red consular está sujeta a un volumen de trabajo que rebasa su capacidad y hay poco espacio para la innovación. Aún no se ha logrado consolidar mecanismos para aprovechar cabalmente la copiosa información disponible para la toma de decisiones y el despliegue de una verdadera inteligencia consular que permita enfocar acciones de manera preventiva. Tampoco se ha logrado resolver el perene problema de la falta de profesionalización y ruta de carrera para los funcionarios que dedican su vida a las labores consulares, a menudo en condiciones muy difíciles. Es un problema sistémico que afecta tanto a diplomáticos de carrera como al personal local que se contrata en condiciones de dudosa legalidad.

La política consular debe evolucionar para fortalecer su capacidad de reacción frente a los cambios estructurales y coyunturales en la relación con Estados Unidos y en las tendencias demográficas y socioeconómicas de la diáspora mexicana. En primer lugar, la cancillería necesita desarrollar una

${ }^{45}$ J. Passel y D. Cohn, op. cit. 
estrategia consular integral, ${ }^{46}$ que articule una visión de conjunto de prioridades y líneas de acción en todos los ámbitos de este quehacer. Deben identificarse tendencias de mediano y largo plazo, establecerse objetivos y prioridades, estrategias para alcanzarlos, recursos suficientes para darle sustento e indicadores para medir el desempeño.

En segundo lugar, se necesita una iniciativa para construir un sistema de inteligencia consular con la finalidad de prever problemas y tendencias, en lugar de estar siempre reaccionando a hechos consumados. La SRE cuenta con amplias fuentes de información propias y tiene acceso a bases de datos censales y de centros de investigación nacionales y extranjeros. Esta información casi no se ocupa. Un repositorio integrado con toda ésta permitiría generar inteligencia consular para la toma de decisiones.

En tercer lugar, la cancillería debe seguir invirtiendo en la innovación, profesionalización y modernización de sus programas. En el área de protección, desarrollar mecanismos innovadores que le permitan atender a muchas más personas, sin que sea necesario que acudan a las sedes consulares. El CIAM es un punto de partida para una estrategia de ciberconsulados con una capacidad de atención de menor costo individual. En el área de servicios, es preciso dar el siguiente salto innovador que permita ofrecerlo a distancia, por internet, para una población cada vez más integrada a la moderna sociedad estadounidense. En el ámbito de las comunidades mexicanas, se necesita aprovechar los importantes éxitos del modelo de construcción de redes para priorizar los programas y enfocarlos en lo que genera el mayor valor para las comunidades y el país.

Nada de esto se podrá hacer, sin embargo, si no se resuelve el problema de los ingresos. La política consular tiene la

${ }^{46}$ Como lo hizo Australia a partir de 2014 al reconocer las nuevas condiciones y la mayor relevancia de lo consular en su política exterior. Véase Alex Oliver, "Travelling responsibly, but further to go: Australia's new consular diplomacy", Australian Journal of International Affairs, 70 (2016), pp. 681-694, DOI: 10.1080/10357718.2016.1220496. 
capacidad de generar buena parte de sus recursos. Con mayores fondos del Presupuesto de Egresos de la Federación y un modesto incremento en algunos derechos que se cobran en el exterior, podría resolverse este problema. No es razonable que el precio de los servicios sea el mismo en México que en el exterior, en donde el costo de su producción es significativamente mayor; imponer un diferencial que permita fondear los programas que benefician a los mexicanos en el exterior se antoja eminentemente razonable y ajustado a las prácticas de otros países.

La política consular de México es un elemento estratégico de su política exterior que se ha innovado, se ha modernizado y se ha profesionalizado en los últimos veinte años. Hay que seguir en esa línea, adecuando la estrategia y la práctica a los cambios en el entorno. Esperemos que la prioridad que por vez primera ha tenido este aspecto de la política exterior se mantenga y fortalezca.

\section{Bibliografía}

Alden, Chris, y Amnon Aran, Foreign policy analysis: new approaches, Nueva York, Routledge, 2016.

Allen, Brian, Erika M. Cisneros y Alexandra Téllez, "The children left behind: The impact of parental deportation on mental health", Journal of Child and Family Studies, 24, núm. 2 (2013), pp. 386-392.

“Atención a población vulnerable: Niñas, niños y adolescentes no acompañados atendidos por la red consular de México en EUA", Datos abiertos, Gobierno de México (sitio de internet), https://datos.gob.mx/busca/dataset/atencion-a-poblacionvulnerable-ninas-ninos-y-adolescentes-no-acompanados-atendidos-por-la-red-

Ayón, David, "La política mexicana y la movilización de los migrantes mexicanos en Estados Unidos”, en Carlos González Gutiérrez (coord.), Estado-diáspora: la perspectiva de América Latina y el Caribe, t. 1, México, Miguel Ángel Porrúa, 2006, pp. 113-144. 
Bardach, Eugene, y Erick M. Patashnik, A practical guide for policy analysis: The eightfold path to more effective problem solving, Thousand Oaks, CK Press, 2015.

"Centro de Información y Asistencia a Mexicanos", Gobierno de México, Secretaría de Relaciones Exteriores, sRE, https://www. gob.mx/ciam

DÉlano, Alexandra, "The diffusion of diaspora engagement policies: A Latin American agenda”, Political Geography, 41 (2014), pp. 90-100.

Durand, Jorge, Douglas S. Massey y Chiara Capoferro, "The new geography of Mexican immigration”, en Víctor Zúñiga y Rubén Hernández León, (eds.) New destinations: Mexican immigration in the United States, Nueva York, Russell Sage Foundation, 2005, pp. 1-20.

González-Barrera, Ana, y Jens Manuel Krogstad, "What we know about illegal immigration from Mexico", 3 de diciembre de 2018, Pew Research Center, http://www.pewresearch.org/ fact-tank/2017/03/02/what-we-know-about-illegal-immigration-from-mexico/

Hanson, Gordon H., The Economic Logic of Illegal Immigration, Nueva York, Council on Foreign Relations, 2007.

Hernández-León, Rubén, y Víctor Zúñiga, V. (2016). "Introduction to the Special Issue: Contemporary Return Migration from the United States to Mexico-Focus on Children, Youth, Schools and Families", Mexican Studies/Estudios Mexicanos, 32, núm. 2 (2016), pp. 171-181.

Hernández Joseph, Daniel, Protección consular mexicana, México, Porrúa, 2015.

Hirschman, Charles, y Douglas Massey, "Places and peoples: the new American mosaic", en Douglas S. Massey (ed.), New Faces in New Places: The Changing Geography of American Immigration, Nueva York, Russell Sage Foundation, 2008.

JACKSON, Robert y Georg SøRENSEN, Introduction to international relations: theories and approaches, Oxford, University Press, 2016.

Johnston, Michael Francis, Stavros Karageorgis e Ivan Light, "Mexican Population Growth in New us Destinations: Testing and Developing Social Capital Theories of Migration using 
Census Data”, Journal of Ethnic and Migration Studies, 39 (2013), pp. 1479-1505, Dor: 10.1080/1369183X.2013.815430.

Ley de Nacionalidad, Diario Oficial de la Federación, 23 de abril de 2012, http:/ / www.diputados.gob.mx/LeyesBiblio/pdf/53. pdi

Massey, Douglas S. y Kerstin Gentsch, "Undocumented migration to the United States and the wages of Mexican immigrants", International Migration Review, 48 (2014), pp. 482-499.

Oliver, Alex, "Travelling responsibly, but further to go: Australia's new consular diplomacy", Australian Journal of International Affairs, 70 (2016), pp. 681-694, DOI: 10.1080/10357718.2016.122 0496.

PAssel, Jeffrey S. y D’Vera Cohn, "Us Unauthorized Immigrant Total Dips to Lowest Level in a Decade”, Pew Research Center, 17 de noviembre de 2018, http:/ / www.pewhispanic.org/2018/11/ 27/u-s-unauthorized-immigrant-total-dips-to-lowest-level-in-adecade/

Passel, Jeffrey S., D’Vera Cohn, Jens Manuel Krogstad y Ana GonZALEZ-BARRERA, "As growth stalls, unauthorized immigrant population becomes more settled”, Pew Research Center, 3 de septiembre de 2014, http://www.pewhispanic.org/2014/09/ 03/as-growth-stalls-unauthorized-immigrant-population-becomes-more-settled/

"Personas mexicanas fallecidas en el el extranjero: repatriación de cadáveres", Datos abiertos, Gobierno de México (sitio de internet), https://datos.gob.mx/busca/dataset/personas-mexicanas-fallecidas-en-el-extranjero-repatriacion-de-cadaveres

Plan Nacional de Desarrollo 2007-2012, Gobierno de la República, http://pnd.calderon.presidencia.gob.mx/index.php?page= documentos-pdf

Plan Nacional de Desarrollo 2013-2018, Gobierno de la República, https://www.dof.gob.mx/nota_detalle_popup.php?codigo $=5$ 299465

Secretaría de la Función Pública, "Informe ejecutivo sobre la evaluación de procesos aplicada al programa 'E003 Expedición de Pasaportes y Servicios Consulares' ”, 2010, https://www.ce neval. org.mx/Informes/Evaluacion/Procesos/Procesos_ 20 
10/SRE/EPR_10_SRE_PASAPORTES.pdf\#search=SRE $\% 20$ 2010

Secretaría de Relaciones Exteriores, "Protección preventiva", 30 de julio de 2015, https://www.gob.mx/sre/acciones-y-programas/proteccion-preventiva-8286

Secretaría de Relaciones Exteriores, "Protocolo para la atención consular de niñas niños y adolescentes migrantes no acompañados", 18 de octubre de 2018, https://www.gob.mx/sre/do cumentos/protocolo-para-la-atencion-consular-de-ninas-ni nos-y-adolescentes-migrantes-no-acompanados-13061

"Ventanilla de Asesoría Financiera: Program Insights for the Field", 2016, CitiCommunityDevelopment.com, Secretaría de Relaciones Exteriores, SRE, https://www1.nyc.gov/assets/dca/downlo ads/pdf/partners/VentanillaReport.pdf

United States Census Bureau, American Fact Finder (base de datos en línea), 2015, https://www.census.gov/

\section{ENTREVISTAS}

Cárdenas Suárez, Héctor, entrevista con Jacob Prado, embajador y director general de Protección a Mexicanos en el Exterior, 11 de julio de 2018.

Cárdenas Suárez, Héctor, entrevista con Juan Carlos Mendoza, embajador y presidente del Instituto de los Mexicanos en el Exterior, 11 de septiembre de 2018.

Cárdenas SuÁrez, Héctor, entrevista con Olga García Guillén, embajadora y directora general de Servicios Consulares, 6 de agosto de 2018.

Cárdenas Suárez, Héctor, entrevista con Sergio Alcocer Martínez de Castro, exsubsecretario para América del Norte, 24 de octubre de 2018. 
